\title{
INFORMATION ON PRIMARY PREVENTION OF RISK BEHAVIOUR INTERNATIONAL CONFERENCE
}

\author{
Jitka Skopalová
}

On 31 October and 1 November, 2016, the 13th international conference called Primary Prevention of Risk Behaviour was held, this time subtitled: "What do we do when we do minimal preventive program?" The conference was primarily focused on the issue how to arrange all thematic areas of the minimal preventive program for all age groups of children at school. What the continuity and compatibility of partial preventive programs really mean. The issues of providing better exchange of mutual information on school prevention programs and their training were also discussed. Another discussed topic concerned the issue whether the word "complexity" is currently duly or excessively used and whether a specific preventive program can really be complex and whether the schools know where and how to search partial programs for their MPP. The conference was aimed not only at bringing as many practical findings, skills and pieces of experience from creation and application of the minimal preventive program at school as possible, but also at understanding and correctly applying its internal structure and mutual interconnection. The conference served also to present current results of research in the area of risk and addiction behaviours, procedures and good practices, and to show tools of primary prevention applied at schools and school facilities. The conference included workshops (e.g. on cooperation of the school and district prevention methodist, Inspection is not Inquisition, reduction of risks, etc.) and a poster section. The conference reflected the current development in the area of prevention not only in our country but also worldwide.

The Primary Prevention of Risk Behaviour conference is a unique event in the Czech Republic and it is intended for a very broad target group - teachers, pedagogical workers, educators, school prevention methodists, psychologists will primarily find interesting topics there, but also other professionals - health care workers, addictologists and policemen will be interested. The conference is traditionally organized by the Addictology Clinic of the 1st Medical School of Charles University and of the General University Hospital together with the Municipal authority of Prague, the Czech Ministry of Education, Youth and Physical Education and SCAN, assoc. (a non-governmental non-profit organization of association type. The association groups experts of individual professions interested in the issue of addictive diseases). 
The $14^{\text {th }}$ conference, focused on the topic of Prevention in Provinces as Parts of One Puzzle, will be held on 18.-19. 9. 2017 (see www.pprch.cz).

\section{Author}

doc. PhDr. Jitka Skopalová, Ph.D.

Faculty of Public Policies, Silesian University in Opava

The Institute of Pedagogical and Psychological Sciences

Bezručovo nám. 885/14, 74601 Opava, The Czech Republic

jitka.skopalova@fvp.slu.cz 